\title{
PRÉ-VESTIBULARES ALTERNATIVOS: DA IGUALDADE À EQÜIDADE
}

\author{
ELENY MITRULIS \\ Centro Universitário Monte Serrat \\ mitrulis@uol.com.br
}

\section{SÔNIA TERESINHA DE SOUSA PENIN}

Faculdade de Educação da Universidade de São Paulo

sapenin@usp.br

\section{RESUMO}

Este artigo examina as crescentes demandas por acesso ao ensino superior em período em que se assiste a um deslizamento do debate sobre igualdade de oportunidades do plano da educação obrigatória para o terreno da educação superior. Representando os interesses dos novos grupos de concluintes de educação básica, proliferaram, a partir do final dos anos 90, dentro de movimentos sociais voltados para segmentos desassistidos da população, cursos preparatórios ao ensino superior, gratuitos e sem fins lucrativos. No âmbito das universidades públicas do Estado de São Paulo, igualmente sensíveis às urgências sociais da inclusão, registram-se também ações favoráveis ao acesso e à permanência desses segmentos sociais nos cursos oferecidos. O artigo analisa as ambigüidades e as aberturas presentes em programas preparatórios ao ensino superior, tomando como referência o Programa Pró-Universitário, voltados aos alunos da série terminal da educação básica, pertencentes à rede estadual de ensino, desenvolvido pela Universidade de São Paulo em parceria com a Secretaria de Estado da Educação. Traz uma análise do perfil dos alunos participantes e uma reflexão sobre os efeitos desse tipo de iniciativa sobre a relação dos jovens com o saber e sobre a construção de suas identidades. Sugere que a ação afirmativa para a inclusão de jovens dos segmentos populares em instituições públicas de ensino superior requer uma proposta educativa na qual a socialização e a aprendizagem estejam intimamente ligadas. O domínio dos saberes preparatórios aos exames de acesso deixa de ser considerado apenas pelo valor instrumental e adquire outros significados como uma nova maneira de ver o mundo, relacionar-se consigo mesmo e com o outro.

CURSO PRÉ-VESTIBULAR - AÇÃO AFIRMATIVA - ACESSO AO ENSINO SUPERIOR EDUCAÇÃO COMUNITÁRIA 


\section{ABSTRACT}

ALTERNATIVE COURSES FOR COLLEGE ENTRANCE EXAMINATION: FROM EQUALITY TO EQUITY. This work explores the growing demands for increasing access to higher education at a time when discussions on equality of opportunities at the level of compulsory education are shifting to higher education. Since the late 90s, free and non-profit higher education preparatory courses, representing the interests of new groups of pupils completing basic education, have been on the rise in social movements oriented towards underprivileged segments of the population. Public universities of the State of São Paulo, also sensitive to the social needs of inclusion, have also taken actions favoring access and permanence of these social segments in their courses. This work analyzes the ambiguities and openings found in preparatory programs for higher education, referring to the ProUniversity Student Program, which was developed by the University of São Paulo in partnership with the State Secretariat of Education, focusing on pupils from the state school system, studying at the last grade of basic education. This study provides a profile of the students, analyzing the effects of this type of initiative on young people's relations with knowledge and on the construction of their identities. It suggests that an affirmative action for inclusion of young people from popular segments of society in public institutions of higher education requires an educational approach in which socialization and learning are closely connected. The acquisition of preparatory knowledge to do access exams is not seen solely for its instrumental value. In fact, it acquires other meanings such as a new way of looking at the world and of relating to the self and the other.

JUNIOR COLLEGES-AFFIRMATIVEACTION-HIGHEREDUCATION-COMMUNITY EDUCATION

Assistimos, nos últimos anos, a expansão dos cursos pré-vestibulares dirigidos a segmentos específicos da população com o propósito de promover maior oportunidade de acesso ao ensino superior, em que são historicamente sub-representados. As políticas de educação de caráter universalista, orientadas pela lógica da oferta, não lograram cumprir a promessa de tratar a todos igualmente, o que tem alimentado forte tendência para a adoção de políticas inspiradas na lógica da demanda, as quais tomam o direito à diferença como base do direito à igualdade. Vários estudos alertam para os riscos de fragmentação e dispersão quando políticas focalizadas tornam-se prioritárias. Hoje, porém, já se admite que, limitados os seus riscos e mantidas as responsabilidades públicas com políticas universais, as políticas de ação afirmativa têm um potencial não desprezível de ampliar o leque de opções para a construção de uma sociedade justa e democrática, adotando estratégias de intervenção que privilegiam grupos sociais em desvantagem. Afonso (2003), ao propor os elementos para uma agenda de in- 
vestigação no campo das políticas educacionais, chama a atenção para a oportunidade de se explorar o surgimento de formas novas e mais híbridas, que articulam práticas de regulação e de emancipação social.

Este ensaio analisa as ambigüidades e as aberturas presentes em programas de ação afirmativa para acesso ao ensino superior público, tomando como referência um programa desenvolvido com alunos da série terminal do ensino médio pertencentes à rede estadual de ensino do Estado de São Paulo.

No final dos anos 90 e início da primeira década do novo milênio, a expansão do ensino superior tornou-se uma questão premente na agenda das políticas públicas como fator de crescimento e desenvolvimento social. As transformações ocorridas no período provocaram a demanda dos cidadãos por níveis cada vez mais elevados de escolarização. As dificuldades de inserção no mercado de trabalho, decorrentes dos processos de internacionalização da economia e do desenvolvimento tecnológico, bem como a globalização cultural contribuíram para intensificar as pressões dos jovens para o ingresso no ensino superior com vistas a uma inserção mais favorável na sociedade contemporânea. A análise de Filmus (2002) sobre a condição dos jovens do ensino médio na América Latina identifica uma situação distinta da que se verificava há algumas décadas, em que níveis mais elevados de escolaridade respondiam pela ascensão social dos segmentos da população que a ela tinham acesso. Hoje, os jovens são desafiados a estudar cada vez mais para manter a posição social em que se encontram.

Por sua vez, as políticas universalistas de democratização do ensino, a despeito de suas limitações, levaram o país a um reconhecido avanço na questão do acesso e da vinculação de recursos. A transformação do ensino médio em etapa final da educação básica, a se tornar progressivamente universalizada, e as políticas de correção de fluxo no ensino fundamental, como a organização de classes de aceleração, as medidas de recuperação, o combate à evasão, a adoção do regime de ciclos, resultaram em aumento significativo das matrículas nesse nível de ensino, notadamente no Estado de São Paulo que concentra a maior taxa de atendimento do país.

Segundo o Plano Nacional de Educação - PNE -, em 1997, de uma população de 17 milhões na faixa de 15 a 19 anos, apenas 6 milhões estavam no ensino médio, 53,8\% dos quais com defasagem série-idade. Entretanto, dados da série histórica que percorre a última década do século $X X$ e o pri- 
meiro lustro do século XXI revelam uma tendência de crescimento significativo na cobertura desse nível de ensino. No Estado de São Paulo, a rede estadual de ensino médio, que responde por $85 \%$ do alunado, chegou a incorporar 11\% e 10\% de novas matrículas anuais, nos anos de 1997 e 1998 respectivamente. Um aumento que correspondeu a aproximadamente 100 mil novas matrículas anuais, resultante das políticas afirmativas no ensino fundamental e da crescente valorização da educação pelos estudantes, suas famílias e pela sociedade em geral.

Essa tendência tornou-se mais moderada nos anos seguintes e dados divulgados pelo Instituto Nacional de Estudos e Pesquisas Educacionais - Inep -, referentes a 2005, indicam redução de matrícula nos estados de São Paulo, Santa Catarina e Rio Grande do Sul, que mantêm expressivas taxas de atendimento no ensino médio. No Estado de São Paulo, os registros revelam uma queda que chega a $-7,2 \%$ na rede estadual e $-6,5 \%$ no total das redes.

Estudos e análises começam a ser realizados procurando identificar prováveis fatores que intervêm nessa nova situação. Um dado a se considerar é que a maior queda ocorre entre os que estão acima da faixa etária correspondente a este nível de ensino, 15 a 17 anos, alimentando hipóteses que vão desde fatores econômicos, evasão em razão de trabalho, a fatores combinados que incluem as políticas de regularização de fluxo adotadas.

De qualquer forma, a explosão de demanda por educação superior nos últimos anos é uma realidade e a expectativa de que se mantenha procede, em vista da grande demanda reprimida. Em comparação com países vizinhos da América Latina, a extraordinária expansão verificada no Brasil nos últimos quarenta anos é insuficiente para atingir uma taxa de escolarização bruta que se aproxime do patamar por eles já alcançado. Segundo dados divulgados pela Unesco, referentes aos anos 1999/2000, o Brasil figura com uma taxa de I5\% de matrículas no ensino superior enquanto Chile e Argentina apresentam taxas respectivas de 38\% e 48\%.

Outro aspecto a considerar é a mudança que ocorre não apenas nos indicadores educacionais, mas também no perfil dos egressos do ensino médio, considerados até pouco tempo um pequeno grupo de heróicos sobreviventes da educação básica. Trata-se de estudantes de perfil altamente heterogêneo do ponto de vista da origem socioeconômica, das experiências culturais e dos percursos escolares, estes em geral acidentados. Boa parte desse alunado 
é oriunda de famílias que não lograram sequer completar os anos iniciais da educação fundamental.

Com o conseqüente aumento dos egressos do ensino médio público, agora formado por um contingente maior de representantes dos extratos majoritários da sociedade, eleva-se o questionamento do princípio de igualdade de oportunidades que pautou a expansão da escola pública por meio de políticas homogeneizadoras, as quais vieram a favorecer sobretudo a grupos restritos, portadores de privilégios econômicos, sociais e culturais.

Os exames de ingresso no ensino superior são uma realidade que remonta à época do Brasil Colônia. Ganham a designação de exames vestibulares com a Reforma Carlos Maximiliano em 1915 e vão, com o passar dos anos, acentuando seu caráter seletivo, destinado ao que pretendia ser a formação da elite dirigente do país. Mesmo nos momentos de maior flexibilização, o acesso ao ensino superior contou com a estrutura do ensino médio para manter vivo o seu caráter seletivo. $\bigcirc$ perfil propedêutico do ensino médio serviu, durante a maior parte de sua existência, como um ritual de passagem ao qual poucos conseguiam sobreviver.

Como decorrência, surgiram os cursos preparatórios aos vestibulares, que se expandiram na proporção em que aumentava a demanda pelo ensino superior e a necessidade de maior qualificação da mão-de-obra. São cursos de natureza lucrativa, especializados por áreas, dirigidos aos segmentos mais favorecidos da população e que, por décadas, têm alimentado o caráter seletivo do ensino superior, legitimado como a expressão verdadeira de uma política de igualdade de oportunidades e mérito.

A sociedade contemporânea enfrenta, contudo, novos desafios que resultam das mudanças ocorridas nos últimos tempos, com reflexos nos vários campos de atividade humana. De um lado, o atendimento à demanda crescente por um melhor preparo da população do ponto de vista educacional, para que ela possa conviver com os avanços alcançados no domínio tecnológico, produtivo e econômico, bem como usufruir desse progresso. De outro, e não menos primordial, o desafio ético de construção de uma ordem social baseada na justiça e no reconhecimento da igualdade básica entre os homens, diante dos efeitos perversos da desigualdade e da exclusão social.

Nesse contexto, a discussão sobre igualdade de oportunidades e educação, que se restringia aos limites da educação obrigatória, alcança os muros 
da universidade e pressiona por um novo exame do significado de conceitos que estão na base dos princípios de autonomia, excelência e mérito, tendo como referência prioritária sua relevância social.

A Declaração Mundial sobre Educação Superior no Século XXI, de I998, reproduz o art. 26, §। da Declaração Universal dos Direitos Humanos, segundo a qual a admissão à educação superior deve ser baseada no mérito, capacidade, esforço, perseverança e determinação dos seus candidatos. Nesse sentido, continua a dar preferência a uma política baseada no mérito individual, agora, porém, com base em uma visão da educação superior considerada componente de um sistema contínuo de educação, vinculada aos demais níveis educacionais aos quais ela deve promover. Deve ainda ser acessível a todos no decorrer da vida, aberta a qualquer pessoa que tenha completado satisfatoriamente a educação média ou que reúna as condições necessárias para a admissão sem qualquer discriminação, seja cultural, lingüística, étnica ou de grupos menos favorecidos, "pois estes grupos podem possuir experiências e talentos, tanto individual como coletivamente, que são de grande valor para o desenvolvimento das sociedades e nações". Valor a ser considerado quer do ponto de vista ético e moral, relativamente ao respeito e à dignidade a que tem direito todo ser humano, quer do ponto de vista econômico, tão caro às sociedades mais orientadas para o mercado e para a competitividade. Uma das descobertas das sociedades do século $X X \mid$ é que pessoas com experiências sociais, culturais, diferenciadas e acostumadas a interagir em ambientes de grande diversidade desenvolvem maior capacidade de responder, com flexibilidade, a novas e variadas atividades e desafios. O convívio social em situações de pluralidade cultural e étnico-racial é considerado como uma das possibilidades de construção de sociedades mais justas e democráticas. Instaurar medidas concretas para promover a participação social e econômica de grupos desfavorecidos é demanda do multiculturalismo democrático.

Nesse sentido, são particularmente reveladores os estudos sobre o perfil dos candidatos e ingressantes nas escolas que oferecem ensino superior gratuito, particularmente nas universidades e nos cursos de maior prestígio acadêmico e social. Os indicadores desses alunos retratam uma situação em que são visíveis os efeitos perversos do princípio de igualdade de oportunidades. No Estado de São Paulo, como já se afirmou, $85 \%$ dos alunos de ensino médio estudam em escolas públicas estaduais. Contudo, apenas 20\% dos apro- 
vados pela Fundação Universitária para o Vestibular - Fuvest - são oriundos dessas escolas. Este é um tipo de constatação que tem fundamentado fartamente as críticas às universidades públicas, conduzidas por interesses os mais diversos.

Da parte daqueles que pretendem contribuir para um processo de expansão e melhoria da universidade pública, no que se refere ao acesso, espera-se que ela seja capaz de separar as questões de mérito de privilégios historicamente mantidos (Santos, 2004). Verifica-se toda uma movimentação nesse sentido, a qual tem contado com protagonistas no interior da própria universidade, em outros aparatos do Estado e entre cidadãos coletivamente organizados.

Vivenciamos, neste início de século, intenso debate sobre inclusão social e persistentes pressões por políticas públicas voltadas para ações afirmativas que assegurem a presença de segmentos da população, até então ausentes, no ensino superior. Ações afirmativas, ou ações de discriminação positiva, são políticas de integração social que têm por objetivo promover o acesso de grupos discriminados à participação nos diferentes setores da vida econômica, política, institucional, cultural e social. Caracterizam-se pelo seu caráter temporário e por propiciarem um tratamento diferenciado e favorável com o propósito de reverter um quadro histórico de discriminação e exclusão que se reproduz por um conjunto complexo de fatores (Jaccoud, Beghin, 2002).

No âmbito do direito, a igualdade jurídica, segundo a qual a lei deve ser igual para todos, abstrata por natureza, é hoje confrontada com experiências e estudos que demonstram sua insuficiência para, por si só, tornar acessíveis aos indivíduos socialmente desfavorecidos as oportunidades de que gozam aqueles socialmente privilegiados.

Joaquim Barbosa Gomes (2005), Ministro do Supremo Tribunal Federal, entende que em lugar de igualdade de oportunidades importa falar em igualdade de condições, e que a noção de igualdade a ser adotada deve ser dinâmica, apoiada na avaliação de desigualdades concretas existentes na sociedade, de sorte que situações desiguais sejam tratadas de maneira dessemelhante, evitando o aprofundamento das desigualdades. Sua proposta é que as ações se pautem pelos princípios da diversidade e do pluralismo, de maneira que se opere uma transformação no comportamento e na mentalidade coletivos, moldados pela tradição, pelos costumes e pela história. É objetivo das políticas afirmativas introduzir transformações de ordem cultural, pedagógica e psi- 
cológica, aptas a subtrair do imaginário coletivo a idéia de supremacia e de subordinação entre grupos sociais, em um projeto de sociedade democrática que assegure a diversidade e a pluralidade cultural e promova condições para o protagonismo, a cidadania e a dignidade pessoal.

Representando os interesses dos novos grupos de concluintes da educação básica, proliferaram, a partir do final dos anos 90, movimentos sociais com um duplo objetivo: preparar segmentos populares para acesso ao ensino superior, mediante a organização de cursinhos pré-vestibulares, gratuitos ou sem fins lucrativos, e pressionar órgãos de governo por ações afirmativas de inclusão social no que tange às oportunidades de continuar os estudos em nível superior. Alguns desses movimentos, de perfil racial, inscrevem-se em uma concepção de ação afirmativa de caráter compensatório, lutando pela reparação de injustiças sociais, enquanto outros, de caráter mais preventivo e racialmente neutros, pautam-se pela idéia de promoção de maior diversidade social, procurando propiciar a ascensão e o fortalecimento de grupos da população sub-representados no ensino superior.

Um estudo realizado por Bacchetto (2003) no Município de São Paulo, entre os anos de 1999 e 2000, identifica 16 cursinhos populares alternativos organizados por iniciativa de movimentos sociais ligados a organizações não governamentais - ONGs - do mais variado espectro, com predomínio daqueles ligados ao movimento estudantil e ao movimento negro. Com exceção de um, com início em 1987, todos os demais começaram suas atividades entre 1996 e 2000, 50\% dos quais com a colaboração de professores voluntários. Com apoios indiretos que vieram de sociedades amigos do bairro, universidades, escolas, igrejas, empresas e outros setores da sociedade, esses movimentos elegeram como foco o atendimento aos grupos sistematicamente excluídos dos bancos universitários, preferencialmente alunos egressos de escolas públicas sem condições financeiras de pagar um cursinho comercial. Ao mesmo tempo, procuraram e procuram formar o aluno para uma visão crítica da sociedade, introduzindo, nos espaços de aula, disciplinas ou temas relacionados a Direitos Humanos e Cidadania, além de propiciarem uma abertura para atividades culturais e orientação vocacional.

Esse quadro, traçado com base em dados do Município de São Paulo, reproduz a situação encontrada em outros municípios e estados da Federação onde é forte a presença de cursinhos pré-vestibulares populares, boa parte 
deles de corte racial, destinados a afro-descendentes. Emerson dos Santos (2005) localiza a origem desse movimento na Região Metropolitana do Rio de Janeiro, onde o Pré-Vestibular para Negros e Carentes - PVNC - inicia, na década de 90, a criação de núcleos destinados a aumentar o nível de escolarização da base social do movimento negro. Segundo o mesmo autor, os cursinhos pré-vestibulares populares de corte racial têm sido um dos principais instrumentos de difusão das agendas do movimento negro brasileiro, disseminando o ideário anti-racista, com particular ênfase na crítica ao mito da democracia racial do país.

Na maior parte desses núcleos o trabalho é voluntário, a coordenação é feita pelos próprios alunos e professores, e as despesas de compra de material didático e ajuda aos mais carentes é feita com módicas contribuições dos alunos. Emerson dos Santos atribui o grande poder de reprodução desse movimento ao fato de os núcleos se constituírem em espaços de embate de leituras do social, em vista da vinculação dos professores selecionados com organizações religiosas, políticas, sindicais de diferentes matizes. Independentemente do grau de subordinação dos núcleos à questão fundadora do movimento dos cursos pré-vestibulares: a questão racial, a disciplina Cidadania e Cultura, cujo conteúdo inclui temas de interesse mais amplo que a preparação para os vestibulares, marca presença como uma forma de se contrapor a um projeto político pedagógico conservador, considerado excludente.

Uma iniciativa inspirada no PVNC, e de expressão no movimento de cursos pré-vestibulares alternativos de caráter racial, é o movimento Educação e Cidadania para os Afro-Descendentes e Carentes - Educafro -, com mais de 10 mil alunos em São Paulo, Minas Gerais, Rio de Janeiro e Espírito Santo. Há, ainda, o Movimento dos Sem Universidade - MSU -, que atua em dez estados da Federação. Sobram indícios de iniciativas isoladas e diversificadas em grande número. Esse é um quadro a ser mais bem investigado.

No entender de Santos, a dimensão política dos pré-vestibulares populares, presente nas suas iniciativas de ações afirmativas, fez com que se tornassem um importante interlocutor social junto às várias esferas de governo. São considerados porta-vozes legítimos dos afro-descendentes, capazes de fazer propostas às políticas públicas de promoção social a esse segmento da população.

Uma das conquistas reconhecidas pelo movimento negro foi a criação, pelo Ministério da Educação em novembro de 2002, do Programa Diversida- 
de na Universidade, Lei n. 10.558, com o propósito de implementar e avaliar estratégias para a promoção do acesso e da permanência ao ensino superior de pessoas pertencentes a grupos socialmente desfavorecidos, com ênfase nas populações afro-descendentes e/ou indígenas. O Programa, ainda em vigor, seleciona instituições públicas ou privadas sem fins lucrativos, com experiência anterior de um ano em gestão de projetos educativos para acesso à universidade, voltados especificamente para afro-descendentes e indígenas egressos do ensino médio, e oferece apoio técnico e financeiro ao desenvolvimento de Projetos Inovadores de Cursos - PIC - com uma carga horária de 900 horas, distribuída em nove meses, incluindo horas letivas, atividades de formação social e acesso a bens culturais. Entre os requisitos técnicos obrigatórios para a proposta do PIC, a ser apresentada pelas instituições candidatas ao programa, estão: definir conteúdo acadêmico consistente e coerente com as Diretrizes Curriculares Nacionais para o Ensino Médio - DCNEM; desenvolver conteúdo e atividades de combate ao racismo, estudo das relações raciais no Brasil, valorização da diversidade racial e étnica; e acesso a bens culturais. A vinculação da proposta ao ideário anti-racista é garantida pela apreciação do material didático do curso que a instituição candidata deve apresentar no ato de inscrição. No ano de 2004, o Programa beneficiou aproximadamente 3.400 alunos, participantes de 27 Projetos Inovadores de Cursos, e, em 2005, contemplou 5.350 alunos, matriculados em 22 projetos desenvolvidos nas diferentes regiões do país.

Há, ainda, outros indicadores que dão conta da sensibilidade do Estado às pressões por ações afirmativas de acesso ao ensino superior. Em 2004, o Ministério da Educação introduziu no documento de reforma do ensino superior uma proposta de ampliação do número de vagas no noturno e trabalhou a adoção do regime de cotas no sistema público. Segundo orientação do MEC, as instituições federais de ensino superior deverão destinar pelo menos 50\% de suas vagas para estudantes de escolas públicas, que por sua vez devem ser distribuídas entre negros e indígenas de acordo com a composição étnica de cada unidade da Federação. No mesmo ano foi instituído o Programa Universidade para Todos - Prouni -, que preconiza uma ação afirmativa de acesso também baseada em critérios raciais e socioeconômicos, a ser aplicada no preenchimento de vagas por alunos oriundos de escola pública e bolsistas de escolas particulares, 30\% das quais reservadas para negros e indígenas. Essas 
vagas são adquiridas no setor privado mediante isenção fiscal. Em 2005, mais de 100 mil vagas foram ocupadas por alunos de baixa renda, dentre os quais 30 mil afro-descendentes. Em 2006 a expectativa é de preenchimento de 200 mil vagas. A idéia subjacente é que o sistema de cotas, em especial nos cursos mais concorridos, trará para dentro da universidade um alunado de perfil que pode ser carente em conteúdos cobrados no vestibular, mas rico em outros, tendo em conta o seu maior conhecimento do país real, em que vive grande parte da população. Aporta assim relevância social às contribuições e responsabilidades da universidade pública

As universidades, por sua vez, pressionadas por diferentes setores da sociedade a contribuírem com um projeto de sociedade democrática e mais justa, têm-se mostrado alertas à necessidade de abrigar um alunado que meIhor corresponda à diversidade social, econômica e cultural da população. Em maio de 2003, um Grupo de Trabalho, instituído pelo Conselho de Reitores das Universidades Estaduais Paulistas - Cruesp -, com o objetivo de analisar a questão da inclusão social, elaborou documento no qual, ao mesmo tempo em que reafirmava seus princípios de excelência acadêmica, autonomia universitária e inclusão social, bem como a centralidade do princípio de mérito para acesso ao ensino superior, mostrava-se sensível à relevância da representação social dos seus candidatos e matriculados, então reconhecidamente limitada a reduzido círculo de cidadãos. O relatório final desse Grupo de Trabalho contém propostas dirigidas ao Estado e às próprias universidades. Ao Estado sugere a criação de bolsas para alunos de ensino médio em desvantagem socioeconômica para freqüentarem cursos pré-vestibulares e uma quarta série opcional sob orientação das universidades para os alunos com potencial, interessados em continuidade de estudos. Às próprias universidades, propõe a ampliação dos projetos de formação continuada de professores, a realização de discussões periódicas sobre os exames vestibulares com professores da rede pública e ações facilitadoras em direção a maior democratização de acesso e permanência aos alunos em desvantagem econômica, entre as quais isenção de taxa de inscrição nos vestibulares, aumento do número de vagas no período noturno, oferta de bolsas de estudos, atendimento médico, moradia e ações para minimizar os efeitos de situações econômicas na evasão de alunos.

Entre 1999 e 2005 o número de isenções de taxa de inscrição ao vestibular na Fuvest saltou de 5 mil para 65 mil, atendendo alunos egressos de es- 
cola pública munidos de declaração de pobreza. Não se pode deixar de registrar que entre 1998 e 2000 foram movidas 42 ações judiciais pleiteando isenção de taxas para vestibulandos carentes e para vestibulandos da rede pública.

A luta pela isenção, contudo, não logrou alcançar os efeitos desejados. $\bigcirc$ índice de abstenção do grupo de candidatos contemplados com a isenção é, em geral, elevado, e o percentual de aprovação, diminuto, I,7\% no exame da Fuvest de 200l. Estudos revelam que, apesar dessas iniciativas, é ainda pequena a proporção de alunos universitários de baixa renda, provenientes de escolas públicas nesse vestibular. As ações para reverter a situação atual ainda são insuficientes. No vestibular de 2004/2005 da Fuvest, 38\% dos candidatos provinham de escola pública, mas apenas 20\% deles logravam efetivamente ingressar na universidade. Em 2005/2006, o número de aprovados de escola pública caiu ainda mais, de 20\% para 18,5\%, isso, como já se registrou neste ensaio, em um cenário em que o ensino público estadual responde por $85 \%$ do total de matrículas do ensino médio.

O monitoramento dessas estratégias diferenciadas de democratização de acesso e permanência no ensino superior possibilitou uma compreensão mais alargada da situação. Uma das idéias que se tem construído nos últimos anos, no seio das universidades públicas paulistas, é que o momento exige a confluência de ações articuladas de mais amplo espectro, envolvendo entidades sociais e órgãos de governo para fazer frente ao desafio e à urgência de ampliar o contingente de população com formação em nível superior, sem descurar o princípio de inclusão social que alerta para a representatividade dos grupos sociais atendidos.

\section{O PROGRAMA PRÓ-UNIVERSITÁRIO DA USP}

Foi como resposta alternativa a essas demandas, que a Universidade de São Paulo, por iniciativa da Pró-Reitoria de Graduação, concretizou uma parceria com a Secretaria de Estado da Educação de São Paulo para o desenvolvimento de um programa com o objetivo de oferecer horas de estudo adicionais a alunos da $3^{a}$ série do ensino médio de escolas estaduais, durante um semestre letivo, com o propósito de facilitar o acesso ao ensino superior público.

A análise dessa experiência designada como Programa Pró-Universitário, feita a seguir, utiliza como contraponto dois outros programas com os quais 
guarda algumas afinidades: o Cursinho Popular de Jandira - CPJ -, criado por lei municipal, e o Centro de Apoio Popular Estudantil - Cape -, desenvolvido no campus da USP de Ribeirão Preto. São três cursos preparatórios ao vestibular que apresentam como traço comum o fato de serem racialmente neutros e de se vincularem seja a iniciativas no âmbito da própria universidade, como o Pró-Universitário e o Cape, seja à experiência universitária, por recrutarem como docentes alunos dos cursos de graduação da USP. São iniciativas que transcendem o propósito estrito de colocar os alunos na universidade. Procuram promover experiências de ensino que lhes possibilitem desenvolver uma relação com o conhecimento que não seja meramente instrumental, mas que contribua para sua formação no plano cognitivo e social como cidadãos ativos, portadores de um cabedal de cultura que lhes permita a formulação de um projeto de vida pessoal com horizontes mais amplos.

O Pró-Universitário resultou de determinado entendimento da Universidade de São Paulo sobre a relevância das variáveis tempo de estudo, ampliação dos espaços de conhecimento e dos contatos com pessoas de referência, no conjunto dos fatores favoráveis à consolidação da formação básica e de um melhor preparo para continuidade de estudos no ensino superior. Pesquisas realizadas confirmam o percentual mais elevado dos que se inscrevem e ingressam no ensino superior após investirem horas adicionais de estudo em complemento ao ensino médio. No caso dos aprovados pela Fuvest nos últimos anos, a maioria freqüentou cursinhos com duração de um semestre a um ano e meio. Uma vez que esse não é um investimento disponível aos alunos oriundos dos segmentos populares da sociedade, caberia às instituições públicas e, em particular às universidades, colaborar para que ele se tornasse exeqüível.

O curso desenvolveu-se de julho a novembro de 2004, com atividades diárias perfazendo 30 horas semanais e um total de 640 horas. Foram oferecidas 5 mil vagas em escolas estaduais da Região Metropolitana de São Paulo distribuídas entre 16 turmas, sendo nove no período diurno e sete, no período noturno (Universidade de São Paulo, 2005).

Os critérios de inscrição dos candidatos ao Programa incluíram: estar devidamente matriculado na $3^{a}$ série do ensino médio regular da rede estadual paulista; não ter repetido nenhuma série desse nível de ensino; ter nota acima de determinado padrão fixado em relação à avaliação externa do rendimento 
dos alunos do Estado de São Paulo; possuir desempenho escolar em 2003 eqüivalente aos conceitos ótimo, bom e regular adotados nas escolas, e freqüência no ano anterior, nunca inferior a 75\%. Em caso de empate, deveriam ser privilegiados os alunos com renda familiar mais baixa. Na maioria das escolas, entretanto, o número de inscrições foi igual ou apenas ligeiramente superior ao número de vagas, o que significa que esses critérios não chegaram a ser propriamente seletivos.

Matricularam-se nas escolas, efetivamente, 3.986 alunos, dos quais permaneceram até o final do Programa pouco mais de 50\%. Entre as principais dificuldades para obter um maior índice de matrículas, segundo depoimentos dos profissionais da rede pública envolvidos e dos próprios alunos, estariam: a insatisfatória divulgação do Programa na rede; a localização das escolas, nem sempre próximas a meios de transporte coletivo; o alto custo de locomoção; o tempo despendido no trajeto para o local do curso.

Verificou-se, nos cinco meses em que o curso se desenvolveu, um contínuo movimento de evasão e de novas matrículas. Uma das hipóteses formuladas refere-se à natureza do Programa, desenvolvido a partir da adesão voluntária de alunos interessados. Sua estrutura e funcionamento diferiram, portanto, do ensino regular pelo caráter não obrigatório e pela natureza apenas diagnóstica das avaliações feitas durante o processo de seu desenvolvimento. Em virtude das dificuldades de preencher as vagas oferecidas, foram realizadas mais quatro chamadas subseqüentes.

O perfil dos alunos do Programa era relativamente homogêneo quanto à faixa etária e origem socioeconômica. A idade variava entre 17 e 18 anos, porque não eram aceitos estudantes com histórico de reprovação no ensino médio. Quanto à origem socioeconômica, participaram estudantes provenientes de famílias de baixo poder aquisitivo; $62 \%$ declararam possuir renda familiar entre 500 e 1.500 reais e 30,7\% situavam-se no patamar inferior a 500 reais. Na maior parte dos casos, uma só pessoa, no máximo duas, contribuía para a obtenção dessa renda. Em 76\% dos casos, 4 a 6 pessoas eram sustentadas por esses proventos.

Uma análise mais minuciosa, feita com base nas respostas ao questionário socioeconômico respondido por 1.963 desses alunos que se inscreveram no vestibular da Fuvest, revelou a preponderância do gênero feminino $(69,7 \%)$ e da cor branca (51,6\%). A proporção dos negros (pardos 36,9\% e pretos 
$8,8 \%$ ) aproximou-se da encontrada na população em geral e distanciou-se bastante da representação desses grupos étnicos entre os estudantes universitários matriculados na universidade. Os indígenas compareceram na proporção irrisória de 0,8\%.

Do total de alunos, 95\% não exerciam profissão remunerada, embora fossem provenientes de famílias com baixo poder aquisitivo. A freqüência ao Programa, concomitante à $3^{\text {a }}$ série do ensino médio, certamente diminuía as possibilidades de uma terceira jornada de atividades em trabalho remunerado.

As dificuldades econômicas dos participantes do Programa ficaram mais evidentes quando se indagou dos estudantes sobre a possibilidade de eles se manterem com seus próprios recursos durante os estudos universitários. Apenas 9,3\% acreditavam que poderiam contar apenas com os recursos da família; 48,8\% pretendiam trabalhar, além de contar com a ajuda da família; e 33,3\% esperavam poder contar com bolsa, muitas vezes complementada com o próprio trabalho.

Não foram observadas diferenças significativas entre a escolarização dos pais e a das mães dos alunos. Esta era, em geral, baixa, ainda que maior que a média da população. Cerca de 60\% dos pais e 52\% das mães cursaram apenas o ensino fundamental, e a maioria não o concluiu, mas era maior a proporção de mães que possuíam o ensino médio do que a de pais (33\% e 28\% respectivamente). Poucos eram os pais não alfabetizados e os que fizeram um curso superior.

Outros dados sobre o perfil dos alunos, que complementam o quadro traçado, foram coletados por meio de questionário respondido no final do Programa por 1.568 sujeitos. Observa-se, com base nesse instrumento, que os poucos alunos que afirmaram exercer alguma atividade remunerada despendem nela algumas horas por dia ou trabalham apenas no fim da semana, o que significa que, teoricamente, trata-se de um alunado que tem disponibilidade para estudar e para envolver-se em outras atividades sociais e culturais. Contudo, são jovens com poucas oportunidades de desenvolvimento pessoal no que tange a experiências culturais e de lazer. Entre as atividades realizadas por esses estudantes, as indicadas com maior freqüência são: encontrar os amigos, ouvir música, assistir televisão e ajudar os familiares em casa. Esses jovens, entre 75\% e 94\%, raramente ou nunca vão ao cinema, ao teatro, participam de atividades musicais ou relacionadas a artes 
plásticas ou à dança. Por volta de 50\% têm alguma forma de participação em atividades religiosas e mais da metade dos jovens raramente ou nunca pratica esportes.

Coube a docentes da universidade, especialistas nas diversas áreas, o planejamento do curso, a produção de material de apoio pedagógico, bem como a seleção, capacitação e acompanhamento do trabalho de estagiários, alunos de graduação que atuaram como monitores. Os profissionais da rede pública, professores, coordenadores pedagógicos e vice-diretores, participaram das atividades de coordenação local do Programa.

Os materiais curriculares, especialmente elaborados para o Programa, privilegiaram conteúdos básicos para reforço e consolidação da aprendizagem. O programa do exame de seleção, divulgado pela Fuvest, permaneceu como referência dos estudos que seriam desenvolvidos, uma vez que havia uma preocupação de elevar as possibilidades de inclusão social sem colocar em risco o princípio de mérito e excelência acadêmica.

Apesar dessa característica, que poderia identificar o Programa com os inúmeros cursos preparatórios existentes, particularmente os comerciais, este assumiu aspectos que o distanciaram das características peculiaridades de um cursinho pré-vestibular. Em contraposição ao preparo pontual dos alunos em assuntos ou mesmo questões mais freqüentes nos exames de acesso, o PróUniversitário foi concebido com base em pressupostos educacionais direcionados a fortalecer a formação geral dos alunos. E isso por duas razões: uma de caráter prático e outra de natureza conceitual, teórica. Do ponto de vista prático, preponderou a posição de que uma preparação intensiva de menos de um semestre, sobre uma base ainda não consolidada, teria pouco êxito. Havia que se assegurar a formação geral do aluno. Do ponto de vista conceitual, prevaleceu a disposição de se desenvolver o Programa segundo parâmetros educacionais e pedagógicos que pudessem não apenas propiciar uma formação básica de maior densidade, mas que tivessem, também, o potencial de influenciar avanços e inovações no currículo e nas práticas pedagógicas das escolas de ensino médio. A intenção subjacente era a de estabelecer maior integração entre a educação básica e o ensino superior, visando a meIhoria da qualidade do ensino em todos os níveis.

Em alguns casos, foram incluídos conteúdos considerados relevantes, usualmente não desenvolvidos nesse nível de ensino, como o caso da geome- 
tria em Matemática, ou ainda foram adotadas formas de abordagem do conhecimento, mais favoráveis à produção de significado e à articulação com as experiências de vida dos alunos. De qualquer forma, tratava-se de um material curricular que, embora selecionado com vistas a favorecer o preparo dos alunos para exames de acesso ao ensino superior público, tinha como principal foco prover atividades que possibilitassem uma relação com o conhecimento mais significativa e desafiadora do ponto de vista da formação geral. Não se tratava, propriamente, de cobrir a programação integral divulgada pelas universidades públicas para os vestibulares como já se afirmou. Este foi, porém, um ponto em torno do qual se construíram consensos provisórios durante o desenrolar da experiência. De qualquer forma, alunos e professores, estagiários/ graduandos, encontravam-se orientados uns e comprometidos outros com o sucesso nos exames vestibulares, embora reconhecessem a importância da consolidação da educação básica.

As avaliações contínuas e as avaliações simuladas aplicadas no decorrer do Programa revelavam baixo desempenho e dificuldades comuns entre as diversas disciplinas: ausência de conhecimentos básicos, falta de atenção na leitura das questões, dificuldade de interpretação de enunciados, baixa competência de argumentação. Boa parte do conteúdo apresentado no material de apoio pedagógico, que deveria servir para revisão de conteúdos e consolidação de aprendizagens já realizadas mediante novas formas de abordagem, era desconhecida dos alunos, exigindo mais tempo para ser trabalhada do que o previsto. Nesse sentido, tornou-se inexeqüível o desenvolvimento completo do material de apoio que já consistia em um recorte particular dos programas de vestibulares divulgados. Não surpreende, portanto, que, dos estudantes que responderam ao questionário durante o Programa, apenas 12\% consideravamse preparados para o vestibular e 65\%, parcialmente preparados.

Entre os 1.963 alunos do Programa que se inscreveram para o exame da Fuvest, 73\% admitiram que o curso de cinco meses fora a única oportunidade que tiveram de complementar o seu preparo para o ingresso no ensino superior. Esse tempo reduzido de preparo constituiu de fato um diferencial desfavorável para esses alunos quando comparado com o tempo de preparo do conjunto dos estudantes oriundos de escolas particulares e aprovados na Fuvest. Desses, 60\% cursaram pré-vestibular durante mais de um semestre e até por mais de um ano e meio. 
Estas constatações, juntamente com os índices de aprovação nos vestibulares das universidades estaduais paulistas, fortaleceram a hipótese de que um tempo maior de estudo é uma variável significativa no êxito dos alunos que pretendem acesso ao ensino público superior. Os dados colhidos nas três universidades (Universidade de São Paulo - USP -, Universidade Estadual de Campinas - Unicamp - e Universidade Estadual Paulista - Unesp) indicaram 44 alunos aprovados dentre os 2.494 alunos freqüentes no final do Programa. Os alunos aprovados nesses vestibulares, que freqüentaram boa parte do Programa, mas que não compareceram às aulas, nas duas últimas semanas, não foram contabilizados.

Para se qualificar melhor o índice de aprovação de 1,77\% dos candidatos do Programa Pró-Universitário que prestaram o vestibular, é mister proceder à análise do perfil desses alunos em relação ao perfil dos aprovados na Fuvest e na USP Leste em particular. A USP Leste é a nova unidade da USP localizada na zona leste da cidade de São Paulo, região na qual se concentra numeroso segmento das camadas populares do município. Seu projeto representa uma iniciativa de inclusão social. Além de uma resposta ao crescimento da demanda por ampliação de vagas no ensino superior, a USP Leste tem como propósito contribuir para o desenvolvimento geral e educacional da região, pela aderência de sua proposta às necessidades locais e pela oferta de cursos inovadores ainda pouco procurados pelos candidatos aos vestibulares da USP, em geral. Em 2005, dos candidatos inscritos no vestibular da Fuvest, 40\% eram moradores da Zona Leste. Dos aprovados, 28\% o eram. Analisando o perfil de todos os aprovados na Fuvest e dos aprovados para os cursos da USP Leste, em relação ao perfil dos alunos do Pró-Universitário aprovados na Fuvest, verifica-se que este último grupo é mais representativo da população quanto à origem étnica e à renda familiar.

Enquanto a taxa de aprovação de negros na Fuvest em geral foi de 10\%, e na USP Leste, foi de $21 \%$; este índice atinge 30\% entre os alunos que participaram do Programa.

Mais significativos ainda são os dados referentes ao percentual de aprovados com relação à renda familiar. Enquanto na Fuvest e na USP Leste, respectivamente, $23 \%$ e $40 \%$ pertenciam a famílias com renda mensal inferior a I. 500 reais, entre os alunos do Programa este percentual atingiu a cifra de 92\%. Considerando ainda os dados do questionário que revelam serem eles prove- 
nientes de famílias na maioria de mais de quatro e às vezes mais de seis membros, é possível afirmar que são alunos provenientes dos estratos mais desfavorecidos da população.

\section{COMPARANDO PROGRAMAS COM PROPÓSITOS AFINS}

Confrontando-se a experiência do Pró-Universitário com a dos cursos populares de preparação de egressos do ensino médio para acesso à universidade, desenvolvidas nas cidades de Jandira e de Ribeirão Preto, Estado de São Paulo, verifica-se que há entre elas semelhanças e diferenças significativas que podem oferecer indicações para uma política cultural e de escolarização dirigida à formação dos jovens alunos e egressos do ensino médio.

O Cursinho Popular de Jandira - CPJ - é uma iniciativa da União dos Estudantes de Jandira que, com apoio do Movimento dos Sem Universidade e de outras lideranças do município, elaborou um projeto que, encaminhado à Câmara de Vereadores, foi aprovado em 2002. Uma lei municipal instituiu o cursinho prevendo convênio com o governo municipal e outras esferas de governo, além de parcerias com entidades da sociedade civil, nacionais e estrangeiras. A principal mantenedora é a Prefeitura Municipal de Jandira, mas são realizadas parcerias para contratação de estagiários e aquisição de apostilas. Desde 2005, o CPJ é beneficiário de recursos do MEC para desenvolvimento do Projeto Pedagógico, pagamento de bolsas para alunos e aquisição de equipamentos. Em 2003, o CPJ contava com 780 alunos (Ruedas, 2005).

$\bigcirc$ Cape foi idealizado por um grupo de alunos, ex-alunos, professores e funcionários da USP, Campus de Ribeirão Preto/SP, no início da década de 90. Planejavam criar um centro para alfabetização de adultos, porém, ao pesquisarem a demanda da comunidade, verificaram a necessidade emergente de se preparar as camadas menos favorecidas que visavam acesso ao ensino superior (Bonfim, 2003). Com apoio de uma associação de moradores de bairro, iniciam a primeira turma em 1991 com 30 alunos. Em 1997 foi reconhecido como entidade sem fins lucrativos pela Câmara Municipal da cidade e, entre 1999 e 2002, utilizou dependências disponíveis em institutos do campus da universidade. Conseguiu sede própria em 2003, cujo aluguel é pago com ajuda de empresas e pessoas físicas. Os professores, alunos de graduação e pós-graduação da universidade, além de alguns colaboradores que se 
identificam com a causa, realizam trabalho voluntário. Em 2002 o Cape atendia 170 alunos.

Embora haja diferença na situação escolar dos alunos atendidos, no CPJ e no Cape as vagas são oferecidas a egressos do ensino médio com idades mais avançadas, boa parte deles está envolvida em situações de trabalho, 42\% no CPJ e 68\% no Cape. Nos três programas, a maioria dos alunos é do sexo feminino, mesmo no Cape onde se registra alto percentual dos que trabalham, $60 \%$, e a presença de afro-descendentes aproxima-se da cifra encontrada na sociedade brasileira, $40 \%$ do total de alunos no CPJ.

Assim como no Pró-Universitário, os jovens que participam desses cursos são provenientes de famílias de baixo poder aquisitivo em decorrência da opção pelo critério de seleção socioeconômica. O CPJ contava, em 2004, com $40 \%$ de seus alunos oriundos de famílias de quatro a seis pessoas vivendo com um a três salários mínimos mensais. $\bigcirc$ Cape, por sua vez, após avaliação classificatória de conhecimentos no nível do ensino médio, realiza uma rigorosa seleção socioeconômica eliminatória que conjuga dados documentais e visita domiciliar para confirmar o grau de motivação dos interessados e as informações sobre condições socioeconômicas das famílias.

A evasão aproximada de $50 \%$ nos três programas indica razões ligadas ao tempo dedicado à procura de trabalho, senão à própria dificuldade de conciliar curso e trabalho em termos de horário e mesmo de disposição física, e às dificuldades de acompanhar o curso. Parece pertinente a observação feita por Bonfim (2003) a respeito da evasão de boa parte dos alunos do Cape que vive em condições precárias no limite da pobreza "qualquer episódio inesperado provoca desestruturação, inviabilizando a permanência: doença e/ou morte na família, desemprego, separação, falta de recursos financeiros que garantam a locomoção". Trata-se de uma clientela igualmente excluída do acesso a bens culturais, como livros, teatro, cinema, computador, e a cursos complementares de línguas e informática.

Os três programas são gratuitos, a contribuição de 1 1 \% do salário mínimo no Cape é voluntária, o material didático é cedido. Contudo, as despesas com locomoção e alimentação são significativas para esses estudantes de baixa renda.

A proposta curricular do CPJ reproduz o currículo convencional do ensino médio, a que chamou de parte conservadora, desenvolvida durante os cinco primeiros dias da semana. E acrescenta uma parte intitulada inovadora, 
com a inclusão de uma aula da disciplina Cidadania, realizada aos sábados, com envolvimento de entidades representativas do município, e com o desenvolvimento de projetos para tratar de assuntos e temas da atualidade e projetos de intervenção social, com repercussão na comunidade local. $\bigcirc$ material didático utilizado foi elaborado por alunos e professores da Unicamp.

No Cape o currículo inclui aula de Filosofia aos sábados para discussão de temas atuais que dizem respeito a política, economia e questões ambientais. Seu objetivo é ampliar o nível de conscientização dos alunos e a capacidade de análise. $\bigcirc$ curso não conta com material pedagógico próprio, sendo utilizados livros, xerox, anotações na lousa e transparências como recurso para conduzir as aulas. A prefeitura do Campus de Ribeirão Preto doa mensalmente uma cota de quatro mil fotocópias que são utilizadas de acordo com a necessidade dos professores.

No Pró-Universitário, a formação político cultural dos alunos estava contemplada na proposta de contextualização do programa das disciplinas elaborado pelos professores especialistas. De qualquer forma, monitores/graduandos tiveram a iniciativa de organizar atividades culturais nos domingos e feriados para ampliar os horizontes de análise e compreensão da realidade social. A organização de uma visita ao campus da USP teve um impacto significativo na motivação dos alunos.

O regime de gestão compartilhada adotado nos dois programas diferencia-os do Pró-Universitário, com sua curta duração de cinco meses. Tanto no CPJ como no Cape o processo de gestão foi construído no decorrer dos anos de experiência em direção a uma gestão democrática com a participação de professores/graduandos, alunos, funcionários e mesmo ex-alunos e membros da comunidade. Uma experiência até então desconhecida e valorizada pela maioria dos alunos.

Os dados sobre o índice de aprovação dos alunos desses cursinhos comunitários em exames vestibulares revelam uma situação distinta a ser mais bem investigada. O nível de aprovação no Cape, que entre 1992 e 1999 teria alcançado um índice de 28,4\%, contabilizando instituições públicas e privadas, hoje não pode ser confirmado, visto que não existe uma sistematização de dados a respeito. De qualquer forma, segundo depoimentos dos envolvidos, o que se verifica é que ao aumento do número de candidatos corresponde hoje a uma diminuição no número de aprovados em vestibulares. 
No CPJ, embora o índice de aprovação em 2003 e 2004 em instituições de ensino superior em geral tenha alcançado uma taxa de 6\%, as aprovações em instituições públicas correspondem a 0,6\%, um terço das aprovações alcançadas no Pró-Universitário. No CPJ, a constatação dos baixos resultados de ingresso nos exames de acesso ao ensino superior em anos anteriores, levou à opção de se privilegiar a formação geral, potencializando as aulas de cidadania, os projetos sociais e culturais, as aulas de interpretação de texto e de inglês, com o fito de elevar a auto-estima dos alunos e desenvolver o protagonismo como meio de aumentar competências e habilidades para a vida e não apenas para o vestibular.

\section{QUANDO SE ULTRAPASSAM OS RESULTADOS DOS VESTIBULARES}

Uma análise das repercussões dos programas exige, entretanto, que se ultrapasse o ponto de vista restrito dos resultados expressos nos índices de aprovação nos exames de acesso às universidades públicas do Estado de São Paulo. No caso do Programa Pró-Universitário foram examinadas suas repercussões na formação acadêmica e social dos monitores estagiários, nas escolas da rede pública que o sediaram e, especialmente, na vida escolar e pessoal dos jovens participantes. Igualmente nos dois outros programas foram colhidos depoimentos sobre as mudanças que resultaram da sua participação. A análise é feita, neste ensaio, com base nos depoimentos dos atores envolvidos e nas reflexões teóricas que se seguem.

O número exíguo de alunos do Programa aprovados nos vestibulares das universidades públicas do Estado de São Paulo e o fato de eles não terem se dirigido às carreiras de maior prestígio social tendem a conduzir certos autores à conclusão que ações afirmativas no campo da educação, voltadas para melhorias na formação cognitiva e social, não logram diminuir a seletividade escolar. Esta estaria diretamente ligada à seletividade social e econômica existente no país, sendo, portanto, insuficientes ações focalizadas de discriminação positiva, para assegurar sucesso nos exames de ingresso nas instituições de ensino superior de maior prestígio.

Dados obtidos por Borges e Carnielli (2005) sobre o Programa de Avaliação Seriada - PAS -, adotado pela Universidade de Brasília, indicam que a seletividade social persiste mesmo quando se produz maior integração entre a 
escola básica e o ensino superior e são introduzidas formas inovadoras de seleção. Entre os alunos que ingressaram em cursos de maior prestígio, a maioria não apenas contou com cursinhos preparatórios de maior duração, de um ano a um ano e meio, como recebeu uma educação complementar de alto custo em cursos de informática, língua estrangeira moderna, além de usufruir outros bens culturais.

Contudo, um exame mais acurado dos programas revela aspectos importantes dessas experiências de ação afirmativa que permitem melhor compreensão dos elementos que podem contribuir para aumentar as possibilidades de êxito dos alunos oriundos dos estratos sociais mais populares.

Tedesco (2004), ao analisar as estratégias políticas mais apropriadas para romper os determinismos sociais e culturais dos resultados de aprendizagem, aponta, entre outras opções, para a dimensão pedagógica, com especial ênfase nas chamadas "políticas de subjetividade". Defende, assim como Cury (2005) e outros estudiosos, a primazia das políticas públicas de caráter universal que garantam igualdade de oportunidades educacionais para todos por ser esta a base da cidadania e do domínio dos códigos de acesso ao mundo, condição primordial de formulação de demandas, desenvolvimento pessoal e emancipação. Ambos, porém, reconhecem que, apesar de condições objetivas mais favoráveis em que se desenvolve o processo educativo, em termos de legislação, investimentos e cobertura, as desigualdades no campo da educação persistem e continuam associadas à origem social dos alunos.

Estudos sobre a efetividade da ação da escola, em que pesem os fatores condicionantes de ordem macroestrutural, apontam para a importância de fatores como tempo maior dedicado à aprendizagem, disponibilidade de material pedagógico de apoio que estimule o aluno a uma melhor relação com o conhecimento, domínio pelo professor dos conteúdos a serem ensinados, práticas de ensino diversificadas, abertura para atividades culturais. Estes elementos estiveram, em graus variados, presentes nos programas de ação afirmativa em questão.

Há, porém, uma outra hipótese que tem sido apontada como fundamental para se analisar e formular estratégias de intervenção pedagógica para uma educação de qualidade para todos, não seletiva. Trata-se da relevância da dimensão subjetiva dos atores envolvidos no processo educativo. A esse respeito, Tedesco (2004) argumenta que, embora essa linha de investigação traga o 
risco de uma interpretação das desigualdades educativas mais do ponto de vista pessoal do que socioeconômico e estrutural e, de certo modo, o risco de aliviar as responsabilidades públicas, ela chama a atenção para outros fatores igualmente significativos em uma educação voltada para a formação geral do educando e de particular importância quando se trata da educação dos estratos sociais em situação de pobreza e exclusão social.

Dentre os aspectos de uma política da subjetividade, Tedesco destaca a capacidade de formular um projeto de futuro e a confiança de adultos significativos na capacidade do sujeito. $\bigcirc$ apoio institucional da escola para o desenvolvimento da disposição e capacidade de construir um projeto de vida pessoal numa perspectiva de projeto de sociedade pode ser considerado um aspecto central na formação do aluno. A ausência de projetos parece ser um dos fatores mais significativos na caracterização da pobreza, em virtude das mudanças sociais e econômicas do mundo contemporâneo, que aumentam as incertezas sobre o futuro.

Segundo os monitores/graduandos do Pró-Universitário, os alunos oscilavam, no início do programa, entre a ausência de projetos de futuro e a formulação de projetos irreais, entre o sentimento de que nada é possível e a afirmação de um pensamento mágico, mais relacionado ao desejo do que a um investimento pessoal, de que bastava a presença nas aulas para adquirir as condições necessárias para competir nos exames de seleção. Esta característica é encontrada também por Dubet e Martuccelli (1998) em seus estudos sobre sociologia da experiência. No entendimento desses autores, à escola caberia a responsabilidade de firmar os alicerces para a construção de uma identidade pessoal, multirreferenciada sim, mas capaz de definir objetivos e construir caminhos para sua realização.

Pesquisas mais recentes sobre o valor da confiança na capacidade dos alunos revelam, por sua vez, o peso que as representações de si mesmos e dos professores têm sobre as opções e os comportamentos desses jovens. Indicam que a dimensão cognitiva do processo educativo deve estar integrada à dimensão afetiva e à abertura cultural se se quer eliminar estigmas sociais e estereótipos e contribuir para o empoderamento educacional e político-social desses jovens. Vários desses aspectos estiveram presentes nos programas realizados com os jovens do ensino médio.

Chamados a dar suas impressões sobre o Pró-Universitário, os professores da rede pública envolvidos destacaram o impacto do programa nas repre- 
sentações dos alunos sobre si próprios, sobre os estudos e sobre as possibilidades de ingressar em uma universidade pública. Os depoimentos referem-se ao vazio de perspectivas que geralmente acomete os jovens ao término da educação básica, sem perspectivas de trabalho ou de continuidade de estudos e sem aberturas para a formação cultural pela ausência de equipamentos sociais que os acolham. Os depoimentos que falam da abertura de novos horizontes e da elevação do nível de aspiração desses jovens educandos são eloqüentes:

Pela primeira vez os alunos da escola pública não se sentiram excluídos ao terminar $\circ 3^{\circ}$ ano. Pela primeira vez sentiram-se valorizados e estimulados a lutarem por um objetivo: o de entrar em uma universidade pública e gratuita.

Foi gratificante perceber que voltaram as expectativas de uma vida melhor para nossos alunos que já estavam acostumados com uma vida simples.

Foi a descoberta da possibilidade de crescer, se conhecer, descobrir o próprio potencial. Encontramos pessoas apagadas e deixamos pessoas sonhadoras, traçando objetivos e superincentivadas para a vida.

O Programa desenvolveu nos seus participantes competência para serem em primeiro lugar protagonistas de sua vida, de sua formação, atingindo assim, de forma eficaz, as finalidades atribuídas ao ensino médio.

No caso do Pró-Universitário, os indícios do impacto na vida pessoal e escolar dos alunos estão presentes também nas representações dos próprios alunos que a ele se referem como uma oportunidade que lhes foi oferecida de reescreverem sua biografia, incluindo aí a perspectiva de continuar estudando e o propósito de direcionar os estudos para o acesso a uma universidade pública. Embora entendessem que o programa não fora suficiente para preparálos para o vestibular, os alunos, longe de se sentirem iludidos, mostraram-se estimulados a continuar e a perseguir seus objetivos. A quase totalidade desses alunos, 97\%, expôs sua intenção de realizar novos exames de acesso ao ensino superior nos anos seguintes caso na primeira tentativa não lograssem obter sucesso. A totalidade dos alunos do Cape e do CPJ pretendia continuar tentando lançar mão de expedientes os mais diversos: estudando em casa, pleiteando bolsa de estudos, aliando trabalho e estudo. 
O Programa Pró-Universitário apontara aos alunos um novo horizonte que foi sendo construído pela experiência de novas formas de se relacionar com o conhecimento até então ignoradas e pela mediação de relações interpessoais com seus jovens professores. Alunos e monitores revelam que o direcionamento curricular dado aos conteúdos, pelo seu grau de contextualização e ampliação dos horizontes de análise dos fenômenos sociais e naturais contemporâneos, contribuiu para dar-Ihes maior significado. À medida que os alunos foram aumentando seu interesse e domínio de conhecimento em disciplinas que até então consideravam pouco atraentes ou difíceis de dominar, foram também fortalecendo sua autoconfiança e afastando aos poucos o mito de que alunos de escola pública têm um destino traçado que passa ao largo de um projeto de estudos em universidade pública.

Os contatos dos alunos com os monitores, jovens adultos, ainda estudantes e já possuidores de tantos conhecimentos, exemplos de ascensão social e educacional, boa parte também oriunda de escolas públicas, portadores de visão positiva das suas potencialidades, enquanto postulantes ao ingresso no ensino superior, fortaleceram laços de identificação e os estimularam a elevar seu nível de aspiração e a se organizarem para alcançar os novos objetivos.

Nos três programas, esses jovens monitores, estudantes de uma universidade pública de prestígio, foram vistos pelos alunos como próximos, amigos, e sobretudo como pessoas cheias de iniciativa que lhes ofereciam novos instrumentos para interpretar questões sociais, um mundo de cultura até então pouco palmilhado e uma visão promissora de suas próprias potencialidades e possibilidades. Nos depoimentos a seguir é possível identificar a força da referência na vida das pessoas.

Contribuiu muito com meu aprendizado e para melhorar minhas expectativas, ajudou-me a superar meus medos e me deu muita confiança e coragem para enfrentar o que a vida nos mostra.

Nunca pensei que em poucos meses poderia aprender tantas coisas que não foram ensinadas no ensino médio... não havia freqüentado nenhum cursinho antes e estou adorando este.

O curso me proporcionou grande aprendizado, experiências sociais, políticas, e fez com que eu voltasse a confiar em mim e na capacidade de realização de meus sonhos e objetivos. 
Mesmo se não conseguirmos passar em um vestibular, levamos conosco a lição, que acima de tudo aprendemos, que é nunca desistir, e se sentir capaz.

Os depoimentos colhidos nos dois outros programas são do mesmo teor. O domínio do conteúdo das disciplinas se fez acompanhar de mudanças pessoais, como a valorização das oportunidades, a busca por um objetivo, o amor pela vida e pelas pessoas, a elevação da auto-estima, o valor da persistência e a confiança em si mesmo.

Faziam uma imagem dos seus professores/monitores como pessoas que tinham interesse e investiam na sua aprendizagem. $\bigcirc$ mesmo tipo de representação identificada nos trabalhos de Abramovay (Abramovay, Castro, 2003) e Souza (2003), envolvendo alunos do ensino médio. Para esses, a principal qualidade de um professor é ter interesse pela aprendizagem dos alunos e a principal qualidade da escola é estar mais voltada para a formação dos educandos do que para questões de seu próprio funcionamento. Certamente, duas características marcantes dos programas aqui estudados.

O trabalho desenvolvido na escola tem exigido, nos tempos atuais, uma justificação permanente que requer dos professores um conjunto de atributos de ordem mais ampla do que apenas domínio de conhecimento e competência técnica, a capacidade de ajudar os alunos a construírem um significado para a experiência escolar. No caso dos programas em questão os monitores construíam uma justificação constante das atividades desenvolvidas na perspectiva de um projeto de vida futura que incluía a continuidade de estudos em nível superior. Um exemplo singelo desta atitude assertiva em relação ao futuro dos alunos era a preocupação de municiá-los com informações sobre as instituições de ensino superior, sobre concursos, empregos, bolsas de estudos, e outras oportunidades de interesse para um alunado cursando ou já egresso do ensino médio. Tarefa que parece não ter sido assumida pelo curso regular de nível médio, ou seja, a responsabilidade de preparar seus alunos para os desafios de um futuro quase presente, reproduzindo pela ausência de ações de informação, orientação e apoio a condição de juventude desassistida e individualmente responsabilizada pelo seu próprio destino. Os alunos iniciavam os programas aqui referidos, jejunos de informações sobre exames seletivos, cursos, carreiras, instituições, indispensáveis para suas opções e providências decorrentes. 
Outro impacto favorável do Pró-Universitário na formação dos alunos participantes foi a abertura cultural que propiciou a esses jovens. Com a orientação dos monitores, os alunos conheceram espaços culturais e participaram de eventos, penetraram no mundo da literatura e tomaram gosto pela leitura, foram ao teatro e ao cinema, discutiram filmes, realizaram estudos de campo e despertaram para a necessidade de cultivar um olhar mais voltado para as oportunidades existentes na sociedade. $\bigcirc$ acesso a equipamentos sociais gratuitos em companhia dos monitores contribuiu para o enriquecimento das experiências culturais desses alunos, geralmente restritas a atividades que não implicam custos financeiros. $\bigcirc$ alto percentual destes jovens que não pratica esportes indica a carência de equipamentos sociais de lazer gratuitos e a falta de uma política de investimentos direcionada a essa dimensão importante da sua formação.

\section{ALGUMAS CONSIDERAÇÕES FINAIS}

Os dados parecem indicar que uma ação afirmativa para a inclusão de jovens dos segmentos populares em instituições públicas de ensino superior requer uma proposta educativa na qual a socialização e a aprendizagem estejam intimamente ligadas. $\bigcirc$ tratamento curricular, rico em referências sociais e pessoais significativas, deve ser capaz de suscitar uma relação com o conhecimento não apenas pelo seu valor instrumental, mas primordialmente pelo potencial de construção da própria identidade, da maneira de ver o mundo, de relacionar-se consigo mesmo e com o outro. Os alunos em seus depoimentos falam sobre o que aprenderam e também sobre a importância da experiência para a construção da sua subjetividade, não como coisas distintas. Expressam com alegria o fato de terem compreendido conteúdos que antes não compreendiam, de terem passado a gostar de disciplinas que antes desprezavam. $\bigcirc$ domínio de saberes, nesse caso saberes valorizados para o vestibular, confere a esses alunos a sensação de empoderamento pessoal indispensável ao exercício de uma cidadania ativa, ao desenvolvimento de uma atitude protagonista perante a vida.

Também o convívio com outros significativos, numa relação caracterizada pelo compromisso, pela abertura e pela reciprocidade, contribui para a construção de uma representação de si mais voltada para possibilidades do que 
para limitações. Nos programas em questão, os dados indicam que alguns aspectos da barreira que poderia impedir os alunos de almejarem o acesso ao ensino superior público começaram a ser quebrados.

A análise dos programas de ação afirmativa realizada neste trabalho, ainda que preliminar, sugere questões para o aprofundamento de estudos e investigações e oferece indicativos para maior articulação entre a universidade pública, a rede de ensino oficial e órgãos de governo, na formulação de políticas culturais para a juventude e de políticas de escolaridade no nível médio com potencial mais favorável à democratização do acesso ao ensino superior.

\section{REFERÊNCIAS BIBLIOGRÁFICAS}

ABRAMOVAY, M.; CASTRO, M. G. Ensino médio: múltiplas vozes. Brasília: Unesco, MEC, 2003.

AFONSO, A. J. Estado, globalização e políticas educacionais: elementos para uma agenda de investigação. Revista Brasileira de Educação. Rio de Janeiro: Anped; São Paulo: Autores Associados, n.22, p.35-46, jan./abr. 2003.

BACCHETTO, J. G. Cursinhos pré-vestibulares alternativos no Município de São Paulo (199/2000): a luta pela igualdade no acesso ao ensino superior. São Paulo, 2003. Tese (dout.) Feusp.

BARRETTO, E. S. de S. As Novas políticas para o ensino médio no contexto da educação básica. In: ZIBAS, D.; AGUIAR, M. Â. da S.; BUENO, M. S. S. O Ensino médio e a reforma da educação básica. Brasilia: Plano, 2002. p.353-365

BONFIM, T. A. O Cape em nossas vidas. a visão de um grupo de alunos, ex-alunos e colaboradores sobre um curso pré-vestibular gratuito. Ribeirão Preto, 2003. Dissert. (mestr.) Departamento de Psicologia e Educação/FFCLRP/USP.

BORGES, J. L. G.; CARNIELLI, B. L. Educação e estratificação social no acesso à universidade pública. Cadernos de Pesquisa. São Paulo: Fundação Carlos Chagas, v.35, n. 1 24, p. 1 I 3 139, jan./abr. 2005.

CURY, R. J. Políticas inclusivas e compensatórias na educação básica. Cadernos de Pesquisa. São Paulo: v.35, n. I 24, p. I I-32, jan./abr. 2005.

DUBET, F.; MARTUCCELLI, D. En la escuela: sociología de la experiencia escolar. Buenos Aires: Losadal, 1998. 
FILMUS, D. A Educação média diante do mercado de trabalho: cada vez mais necessária, cada vez mais insuficiente. In: BRALAVSKY, C. (org.) A Educação secundária: mudança ou imutabilidade? Brasília: Unesco, 2002. p. 127-186.

GOMES, J. B. B. A Recepção do instituto da ação afirmativa pelo direito constitucional brasileiro. In: SANTOS, S. A. (org.) Ações afirmativas e combate ao racismo nas Américas. Brasília: Ministério da Educação, Secad, 2005. p.45-79.

JACCOUD, L.; BEGHIN, N. Desigualdades raciais no Brasil: um balanço da intervenção governamental. Brasília: Ipea, 2002.

RUEDAS, S. M. D. Cursinho popular do Município de Jandira: uma experiência educacional visando ao acesso à educação superior. São Paulo, 2005. Dissert. (mestr.) São Paulo: Feusp.

SANTOS, B. de S. A Universidade no século XXI: para uma reforma democrática e emancipatória da universidade. São Paulo: Cortez, 2004.

SANTOS, R. E. dos. A Difusão do ideário anti-racista nos vestibulares para negros e carentes. In: SANTOS, S. A. (org.) Ações afirmativas e combate ao racismo nas Américas. Brasília: Ministério da Educação, 2005. p.229-249.

SOUZA, R. M. Escola e juventude: o aprender a aprender. São Paulo: Educ, Fapesp, Paulus, 2003.

TEDESCO, J. C. Igualdad de oportunidades y política educativa. Cadernos de Pesquisa. São Paulo: Fundação Carlos Chagas, v.34, n. I23, p.557-572, set./dez.2004.

UNIVERSIDADE DE SÃO PAULO; São Paulo (Estado) Secretaria de Estado da Educação. Programa Pró-Universitário: relatório final. São Paulo: USP, Pró-Reitoria de Graduação, 2005. [Relatório final]

Recebido em: março 2006

Aprovado para publicação em: abril 2006 